\title{
THE KINETICS OF THE METHANOL SYNTHESIS ON A COPPER CATALYST: AN EXPERIMENTAL STUDY
}

\author{
A. N. R. BOS, P. C. BORMAN, M. KUCZYNSKI and K. R. WESTERTER ${ }^{\dagger}$ \\ Chemical Reaction Engineering Laboratories, Department of Chemical Engineering, Twente University of \\ Technology, P.O. Box 217, 7500 AE Enschede, The Netherlands
}

(First received 19 September 1988; accepted for publication in revised form 13 February 1989)

\begin{abstract}
The kinetics of the low pressure synthesis of methanol from feed gases containing solely $\mathrm{CO}$ and $\mathrm{H}_{2}$ were studied in an internally recycled gradientless reactor. As experimental accuracy impeded the application of high $C O$ contents, the experimental range of mole fraction of CO was limited to 0.04 to 0.22 . The total pressure was varied from 3 to $7 \mathrm{MPa}$ and the temperature from 503 to $553 \mathrm{~K}$. Residence time distribution experiments confirmed the assumption of perfect mixing on a macroscale. A maximum likelihood approach was used to fit possible kinetic equations. Although more accurate results and better fits - compared to previous experiments in a simple integral reactor were obtained, no single rate expression could be selected as the most appropriate one. This was mainly attributed to the effects of small amounts of $\mathrm{CO}_{2}$ and $\mathrm{H}_{2} \mathrm{O}$ formed in the reactor. Three different reaction rate equations fit the experiments equally well. Arguments are given that we never can expect to elucidate the reaction mechanisms on the basis of kinetic experiments.
\end{abstract}

\section{INTRODUCTION}

In our laboratory research on new, heterogeneously catalyzed processes for exothermic, reversible reactions has been conducted (Kuczynski et al., 1987b; Westerterp and Kuczynski, 1987). The synthesis of methanol by hydrogenation of carbon monoxide using the commercial BASF S3-85 Cu/ $\mathrm{ZnO} / \alpha-\mathrm{Al}_{2} \mathrm{O}_{3}$ catalyst in the absence of carbon dioxide was chosen as a model reaction to study these new processes:

$$
\mathrm{CO}+2 \mathrm{H}_{2}=\mathrm{CH}_{3} \mathrm{OH} \quad \Delta H_{298 \mathrm{~K}}=-91 \mathrm{~kJ} \mathrm{~mol}^{-1} \text {. }
$$

This reaction can be accompanied by several side and consecutive reactions, but under normal operating conditions the modern copper based catalysts are highly selective. In the presence of $\mathrm{CO}_{2}$, the water gas shift reaction-also an equilibrium-has to be taken into account:

$$
\mathrm{CO}_{2}+\mathrm{H}_{2}=\mathrm{CO}+\mathrm{H}_{2} \mathrm{O} \quad \Delta H_{248 \mathrm{~K}}=+42 \mathrm{~kJ} \mathrm{~mol}^{-1} \text {. }
$$

Combining (1) and (2) it can be seen that methanol can also be formed by

$$
\begin{aligned}
& \mathrm{CO}_{2}+3 \mathrm{H}_{2}=\mathrm{CH}_{3} \mathrm{OH}+\mathrm{H}_{2} \mathrm{O} \\
& \qquad \mathrm{H}_{298 \mathrm{~K}}=-49 \mathrm{~kJ} \mathrm{~mol}^{-1} .
\end{aligned}
$$

Due to the lack of reliable kinetic data presented in the literature, especially for $\mathrm{CO}_{2}$-free synthesis gases, it was decided to perform kinetic measurements ourselves. At first instance these were executed in a small integral reactor under conditions which were kept as isothermal as possible. We reported on this previously (Kuczynski et al., 1987a). Pressures and temperatures corresponded to the usual operating conditions of modern low-pressure methanol processes, typically

\footnotetext{
'Author to whom correspondence should be addressed.
}

$6 \mathrm{MPa}$ and $520 \mathrm{~K}$. Out of 17 rate equations, three were found to fit the data equally well. However, we were forced to conclude that the results lacked satisfactory accuracy; among other things we attributed this to the uncertainty of the true reaction temperature. The integral reactor was found to be inherently inadequate for kinetic studies of this type of exothermic reactions. We therefore started experiments in an internally recycled gradientless rcactor, with which we expected better results. The goals of this study therefore were:

(1) to test the applicability of the internal recycle reactor for kinetic experiments and

(2) to obtain a reliable expression for the reaction rate of the methanol synthesis in the absence of $\mathrm{CO}_{2}$ with the BASF S3-85 catalyst.

\section{LITERA TURE SURVEY}

In a previous paper (Kuczynski et al., 1987b) we have reviewed the main articles concerning the kinetics and mechanism of the methanol synthesis on a copper based catalyst. Here we will briefly summarize this survey and expand it with recent findings.

An extensive study on the kinetics of the methanol synthesis has been performed by Natta et al. (1953). Since then catalysts have been improved continuously, resulting in a lowering in process pressures and temperatures from 20 to $30 \mathrm{MPa}$ and $600 \mathrm{~K}$ for the classical high pressure processes, down to $5-10 \mathrm{MPa}$ and $500-550 \mathrm{~K}$ for the modern low pressure processes. Many kinetic studies have been published during the last three decades, but unfortunately, catalysts along with feed gas compositions and operating conditions differed strongly and no final conclusions on the kinetics and the mechanism can be drawn. In particular, in the last 10 years there has been much controversy on the role of $\mathrm{CO}_{2}$ and $\mathrm{H}_{2} \mathrm{O}$, the nature of the active sites and the chemical state of the copper 
component (Campbell, 1987; Chinchen et al., 1987a; Chinchen et al., 1987b; Shub, 1983; Amenomiya and Tagawa, 1984, Bowker et al., 1984). In recent articles (Campbell, 1987; Chinchen et al., 1987a; Shub, 1983) more and more evidence is given that under industrial conditions and for a $\mathrm{CO}_{2}$ containing synthesis gas, a considerable or even predominant part of the methanol is produced from $\mathrm{CO}_{2}$.

Most authors assume Langmuir-Hinshelwood or Eley-Rideal mechanisms, in which one of the adsorption, reaction or desorption steps is considered to be rate determining. Buzzi-Ferraris and Donati (1971) derived in this way the 17 rate expressions given in our previous paper (Kuczynski et al., 1987b). In Table 1 the most important rate equations proposed in the literature are given. To account for the influence of carbon dioxide many authors have included an additional $\mathrm{CO}_{2}$ term in the denominator of their rate expression. Note that this can only describe the retarding effect of carbon dioxide on the reaction rate, found experimentally for relatively high $\mathrm{CO}_{2}$ pressure.

$A$ recent and extensive experimental study on the kinetics and mechanism of the methanol synthesis and the properties of the copper based catalyst has been carried out by Klier and coworkers (Klier et al., 1982; Mehta et al., 1979). Based upon their experimental observations they formulated the following model:

(i) The catalyst can exist in two states: an active oxidized state $A_{\text {ox }}$ and an inactive reduced state $A_{\text {red }}$. The ratio $A_{\text {ox }} / A_{\text {red }}$ is controlled by the ratio $\mathrm{CO} / \mathrm{CO}_{2}$ via the reaction

$$
\mathrm{CO}_{2}+A_{\text {red }}=\mathrm{CO}+A_{\mathrm{ox}} .
$$

(ii) In each reaction step several $A_{\text {ox }}$ centers are involved. The centers can be identified as copper solute species in $\mathrm{ZnO}$.

(iii) All components $\mathrm{CO}, \mathrm{H}_{2}$ and $\mathrm{CO}_{2}$ react in an adsorbed state. $\mathrm{CO}_{2}$, which is the most strongly adsorbed component, competes for active sites with at least one of the species $\mathrm{H}_{2}$ and $\mathrm{CO}$.

(iv) The products are adsorbed weakly.

For the derivation of a rate expression for the methanol synthesis, they assumed the equilibrium (4) to be established and a tri-molecular surface reaction between adsorbed $\mathrm{CO}$ and two molecules $\mathrm{H}_{2}$ to be rate determining. After the introduction of an empirical term for the slow direct hydrogenation of $\mathrm{CO}_{2}$ they derived:

$$
\begin{aligned}
R_{\mathrm{M}}= & k \frac{K^{\prime 3}\left(\frac{P_{\mathrm{CO}_{2}}}{P_{\mathrm{CO}}}\right)^{3}}{\left(1+K^{\prime} \frac{P_{\mathrm{CO}_{2}}}{P_{\mathrm{CO}}}\right)^{3}} \\
& \times \frac{K_{\mathrm{CO}} K_{\mathrm{H}_{2}}^{2}\left(P_{\left.\mathrm{CO} P_{\mathrm{H}_{2}}^{2}-P_{\mathrm{M}} / K_{\mathrm{eq}}\right)}\right.}{\left(1+K_{\mathrm{CO}} P_{\mathrm{CO}}+K_{\mathrm{H}_{2}} P_{\mathrm{H}_{2}}+K_{\mathrm{CO}_{2}} P_{\mathrm{CO}_{2}}\right)^{3}} \\
& +k^{\prime}\left(P_{\mathrm{CO}_{2}}-\frac{P_{\mathrm{M}^{2}} P_{\mathrm{H}_{2} \mathrm{O}}}{K_{\mathrm{eq}, \mathrm{CO}_{2}} P_{\mathrm{H}_{2}}^{3}}\right)
\end{aligned}
$$

for the case in which $\mathrm{CO}, \mathrm{CO}_{2}$ and $\mathrm{H}_{2}$ compete for the same sites. For a constant ratio of $P_{\mathrm{CO}_{2}}$ and $P_{\mathrm{CO}}$, the first of the two terms in this expression is similar to the equation proposed by Natta (Natta et al., 1953). Two equations analogous to eq. (5), with the general form of expression $G$ shown in Table 1, were derived for cases in which different sites are involved. Kinetic measurements were performed in a small integral reactor, using synthesis gases with $70 \% \mathbf{H}_{2}$, the balance being $\mathrm{CO}$ and $\mathrm{CO}_{2}$ with ratios varying from $0 / 30$ to 30/0. A maximum in conversion rate was found for a synthesis gas containing $2 \% \mathrm{CO}_{2}$ and at this optimum the methanol formation rate was approximately seven times higher than in absence of $\mathrm{CO}_{2}$. The equations proposed can account for this optimum. All three rate equations tested fit their data equally well. A typical feature of their equations is that the rate of reaction is zero for gases containing no $\mathrm{CO}_{2}$. In a following article (Vedage et al., 1984) they reported an effect of $\mathrm{H}_{2} \mathrm{O}$ similar to that of $\mathrm{CO}_{2}$ and presented the reaction scheme outlined in Fig. 1.

Liu, Wilcox, Garland and Kung (Liu et al., 1984) performed initial-rate experiments in a batch reactor at $P=1.7 \mathrm{MPa}$ and used feed gases similar to those of Klier et al., but also mixtures containing $\mathrm{H}_{2} \mathrm{O}$. They did not find a maximum, but found that with increasing $\mathrm{CO}_{2}$ content the reaction rates decreased. This was accompanied by an increase in water production. When $\mathrm{H}_{2} \mathrm{O}$ was added in the feed gas, a strong decrease in the methanol formation rate was found: they attributed this to the adsorption of water on the active sites and gained further evidence for this. They suggested as an alternative explanation for the maximum rate found by $\mathrm{K}$ lier that in the absence of $\mathrm{CO}_{2}$ or $\mathrm{H}_{2} \mathrm{O}$, the catalyst is excessively reduced and therefore rather inactive. Addition of small amounts of $\mathrm{CO}_{2}$ prevents this reduction and increases the activity. A further increase in the $\mathrm{CO}_{2}$ content causes an increase in the $\mathrm{H}_{2} \mathrm{O}$ production, so that due to the very strong adsorption of water on the active sites - as confirmed in several experiments - the methanol production rate decreases. In this way a maximum in the activity will be found.

Takagawa and Oshugi (1987) measured reaction rates in a conventional flow reactor al $483-573 \mathrm{~K}$ and 4-10 MPa and proposed power-law equations for the reactions (1) as well as (2) and (3). For reaction (1), in which we are mainly interested, they came up with expression I from Table 1. According to the feed gas composition they classified their experiments into three subgroups: (1) $\mathrm{CO}-\mathrm{H}_{2}$; (2) $\mathrm{CO}_{2}-\mathrm{H}_{2}$ and (3) $\mathrm{CO}-\mathrm{H}_{2}-\mathrm{CO}_{2}$. However, the feed gases from subgroup (1) did contain at least $0.7 \% \mathrm{CO}_{2}$ and the ratio $\mathrm{CO}_{2} / \mathrm{CO}$ amounted at least 0.04 . Again, contrary to Klier et al., no optimal ratio was found. They could not explain the promoting effect in the lower $\mathrm{CO}_{2} / \mathrm{CO}$ range, but they did claim to have evidence that all three reactions, being reaction ( 3 ) in addition to both reactions (1) and (2), have to be taken into account explicitly. The combined effect of the three reaction rates can clarify the conflicting results of Klier et al. 


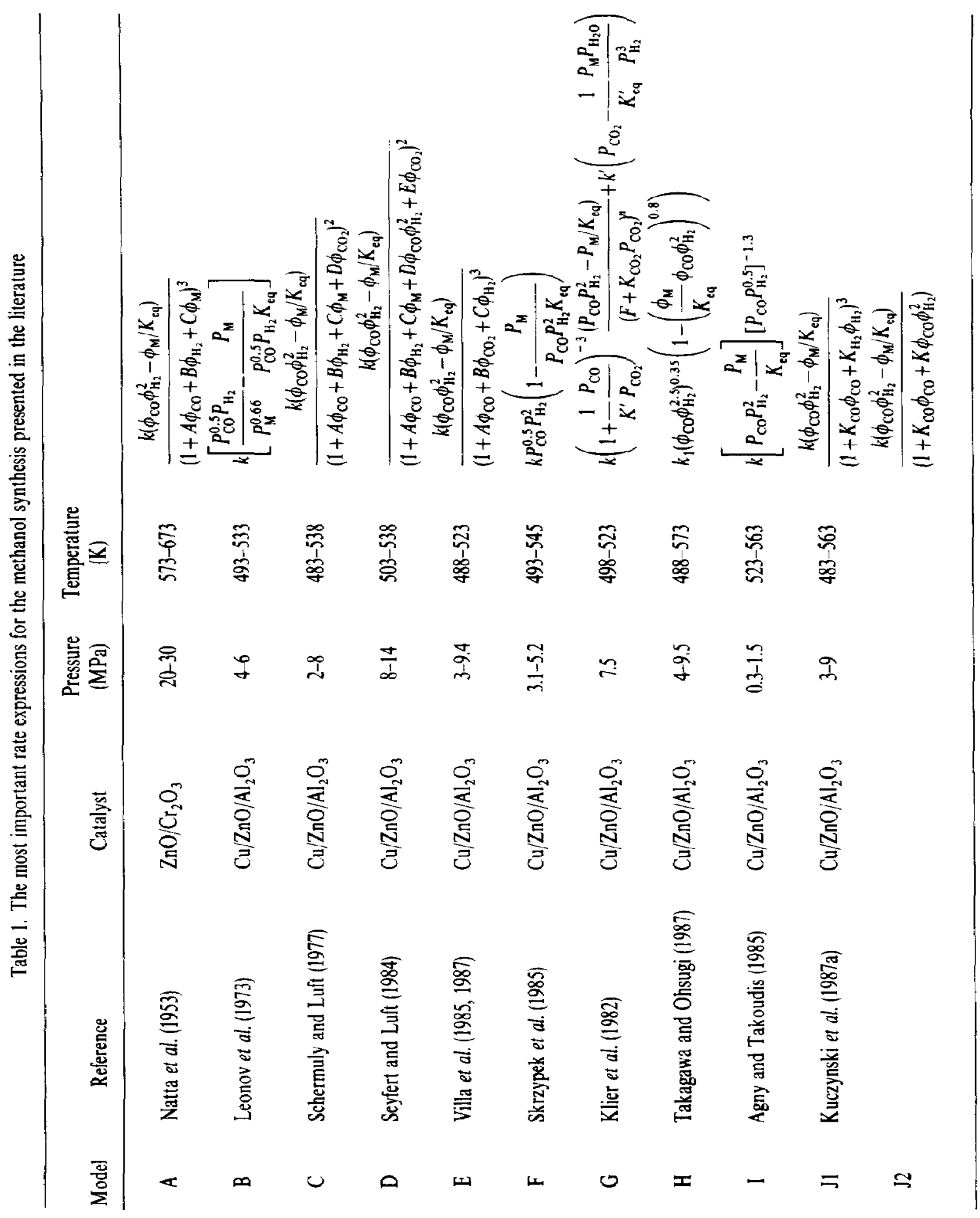




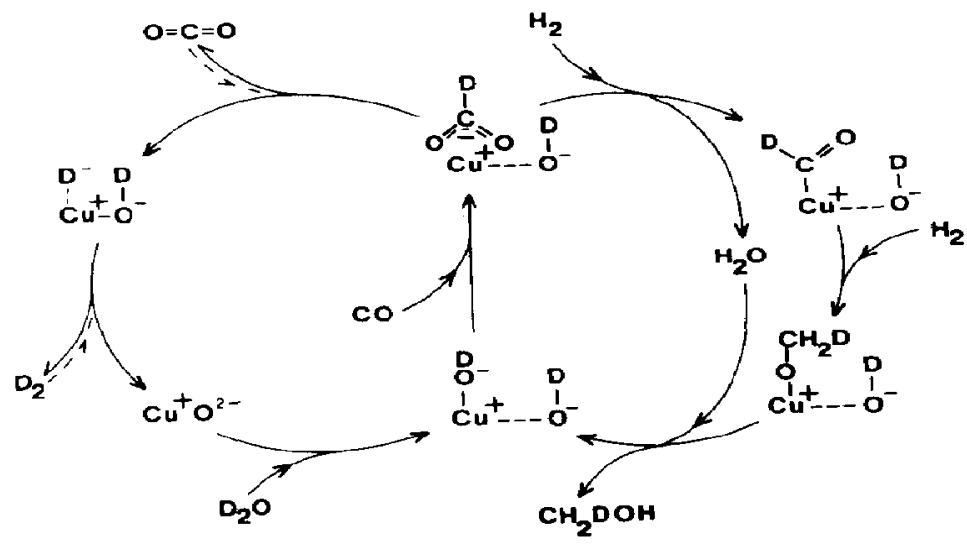

Fig. 1. The mechanism of the methanol synthesis as proposed by Vedege et al. (1984). $\mathrm{D}_{2} \mathrm{O}$, instead of $\mathrm{H}_{2} \mathrm{O}$, has been used to clarify the role of water.

and Liu et al:: due to the contribution of reaction (3) the methanol conversion rate increases with increasing $\mathrm{CO}_{2} / \mathrm{CO}$ ratio, water formation becomes larger too and the strong adsorption of $\mathrm{H}_{2} \mathrm{O}$ on the active sites eventually reduces the activity. According to Bardet et al. (1984), for $\mathrm{CO}-\mathrm{H}_{2}$ mixtures even very small concentrations $\mathrm{H}_{2} \mathrm{O}$ of a few p.p.m. can accelerate the methanol synthesis by a factor of eight, but for $\mathrm{CO}-\mathrm{CO}_{2}-\mathrm{H}_{2}$ mixtures a promoting effect is absent.

Recently, Ghiotti and Boccuzzi presented a review on the methanol synthesis (Ghiotti and Boccuzzi, 1987), mainly on the surface characterisation of several copper based catalysts-e.g. the state of $\mathrm{Cu}-$ not surprisingly, they concluded that, in spite of the large number of recent studies concerning the elementary steps and intermediates, there is no complete agreement yet. They stated that the formation of a formiate species can be regarded as proven-also verified by their own experiments but that nothing conclusive can be said about the sites coordinating these species. $\mathrm{Cu}(\mathrm{I})$ dissolved on the ZnO-surface, Zn(II) or a copper intermediate-with a zinc-bicarbonate formed on a pair of $\mathrm{Cu}$ and $\mathrm{Zn}$ ions as a precursor-may be involved, as well as $\mathrm{Cu}(\mathrm{O}) / \mathrm{Cu}(\mathrm{I})$ sites.

A very extensive review on the mechanism and kinetics of the methanol synthesis was published very recently (Chinchen et al., 1988).

\section{THEORY}

Laboratory reactors for the determination of kinetics

For the determination of the kinetics of heterogeneously catalyzed reactions many types of reactors are available. Basically these can be divided into three groups: the integral reactor, the differential reactor and the recycle reactor. In the latter group, reactors with an internal or an external recycle can be distinguished.

An integral reactor consists of a long catalyst bed and relatively large conversions are achieved. However, this implies a concentration gradient along the reactor length, and, if there are heat effects, a considerable temperature gradient also. This makes a correct evaluation of the data rather difficult and elaborate. In a differential reactor, consisting of a very short catalyst bed, these gradients are absent. However, due to the low conversions, an accurate determination of the reaction rate is not possible unless an extremely accurate method of analysis is available. The recycle reactors combine the advantages of the integral and the differential reactors, without having their disadvantages. Here, after passing through a small catalyst bed, a part of the reactants is recycled. In this way high conversions can be achieved in absence of concentration or temperature gradients.

One of the most popular recycle reactors is the Berty reactor. We have designed and constructed an internal recycle reactor similar to the design of Berty (1974) and shown schematically in Fig. 2. Basically it consists of a basket, in which a variable amount of catalyst can be placed, and a magnetically driven blower for the internal recirculation of gas in the reactor. Dead volumes have been minimised. It allows a kinetic investigation at isothermal, industrially relevant conditions, while mass and heat transfer limitations are largely avoided.

The recycle ratio $R$ is the main parametcr controlling the performance of the reactor. At large recycle ratios-say for $R>R_{\min }$ - the concentration and temperature gradients along the catalyst bed are negligible and a perfect mixing behaviour can be assumed, allowing for a simple evaluation of the kinetic data. For many years the value of around 20 has been taken for $\boldsymbol{R}_{\mathrm{min}}$. (Perfect mixing on a macroscale can be assumed for recycle ratios higher than approximately 8.) In the last few years, it has been recognized that this simple approach can lead to a serious falsification of the data (Wedel and Villadsen, 1983; Broucek, 1983; Cropley, 1987). Here we merely want to point out that residence time distribution experiments give limited information only and that $\boldsymbol{R}_{\min }$ depends strongly on the conversion achieved and the kinetics of the reaction. A major problem is the 


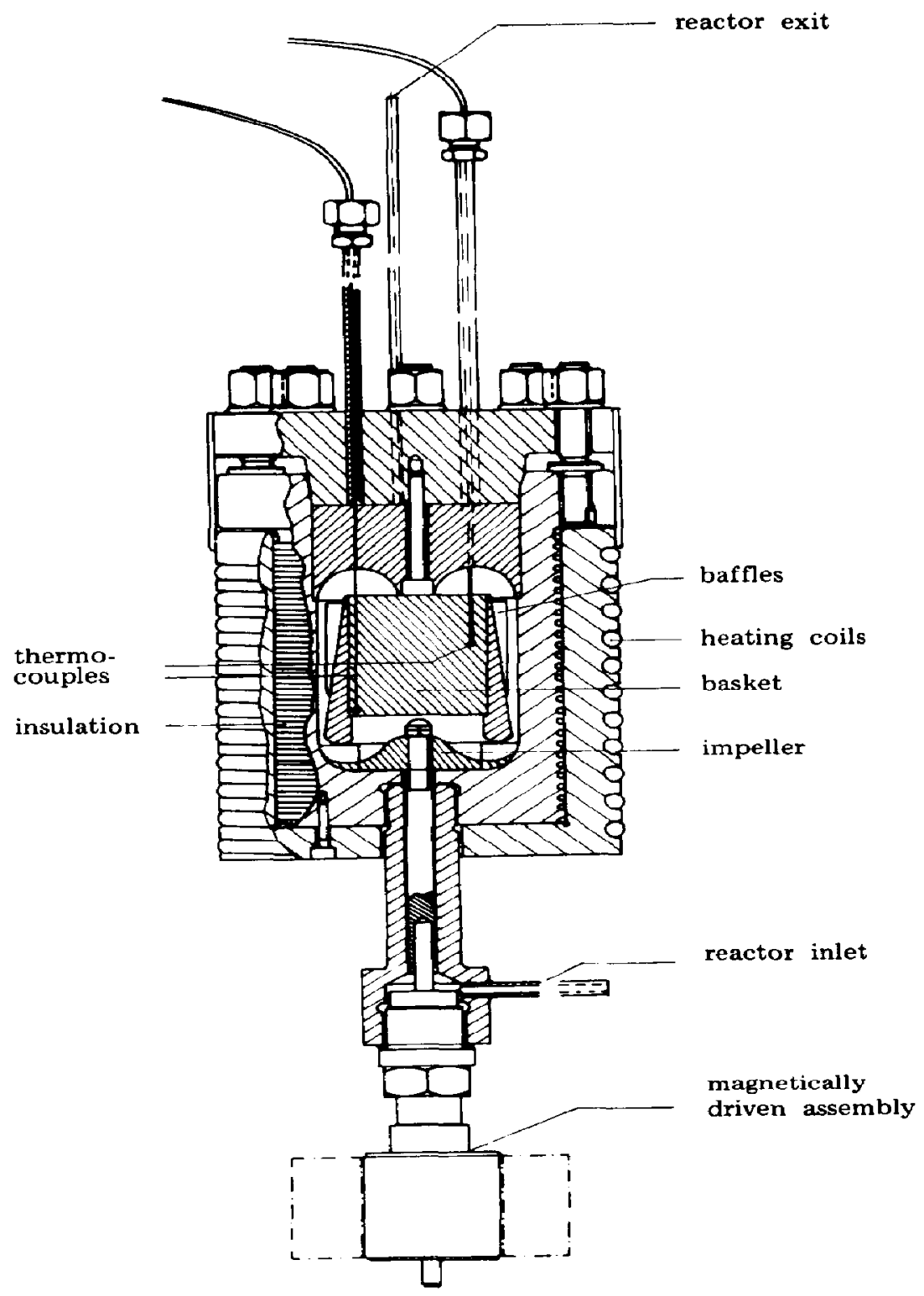

Fig. 2. The internal recycle laboratory reactor in detail.

experimental determination of the recycle ratio. Several methods have been proposed (Berty, 1974; Wedel and Villadsen, 1983), e.g. methods based on the pressure drop over the reactor and the characteristics of the blower, on the measurement of the temperature difference between the gas and solid phase and application of a $N u_{\mathrm{p}}$ correlation, and on the measurement of the temperature rise over the catalyst bed and the assumption that this experimental rise equals the adiabatic temperature rise (Berty, 1974). We have evaluated these methods and in our opinion none of them can provide a reliable estimate of the recycle ratio. This also causes great uncertainties in the evaluation of mass and heat transfer limitations. We feel that for a reliable kinetic study this difficulty of determining the recycle ratio is a serious drawback of a Berty type experimental laboratory reactor.

Recently, Georgepoulos and Broucck (1987) have indicated a promising method based on the difference in conversion between the two configurations as obtained by interchanging the inlet and outlet of the reactor. It can easily and fruitfully be used provided a highly accurate analysis method is available.

Recently, Tiltscher and Hofmann (1987) reported on a new type of recycle reactor, the screw conveyor, in which the foregoing problems might be avoided. 
Residence time distribution in an internal recycle reactor

By means of residence time distribution experiments the assumption of perfect mixing on a macroscale can be verified. The well known function $F(t)$ is defined as the fraction of elements in the outlet flow with a residence time shorter than $t$. For a continuously operated ideally stirred tank reactor (CISTR) it is easy to derive that:

$$
F(t)=1-\mathrm{e}^{-t / \tau} \quad \text { and } \ln (1-F(t))=-t / \tau
$$

This function can be determined experimentally by means of a step input function. For an ideal step signal in the inlet concentration.

$$
\begin{array}{ll}
F(t)=c(t) / c(t=\infty) & \text { if } c(t=\infty) \neq 0 \\
F(t)=1-c(t) / c(t=0) & \text { if } c(t=\infty)=0 .
\end{array}
$$

So, for a CISTR a straight line will be obtained if the logarithm of the concentration-or a signal proportional to the concentration-is plotted against time. A more detailed discussion can be found in many textbooks on chemical reaction engineering, e.g. Westerterp et al. (1984).

\section{Derivation of a reaction rate equation from the exper- imental data}

For the estimation and evaluation of the parameters of the kinetic models, the RKPES computer program developed by Klaus and Rippin (Klaus, 1981; Klaus and Rippin, 1979) was available. This program applies the maximum likelihood approach and a Marquardt optimization algorithm. In general this program can be used to estimate the parameters $\theta$ in a model of the form:

$$
\mathbf{y}=f(t, \mathbf{x}, \boldsymbol{\theta}, \mathbf{y})
$$

in which $y$ is the response vector-both single and multi response models can be tackled-containing response variables subject to a specified experimental error distribution, $\mathbf{x}$ is the vector of independent variables which are assumed to be free of error, and $\theta$ is the parameter vector. Our system, in which the synthesis gas is fed to an internal recycle reactor and the methanol formed is removed from the product gas by condensation, can be described by a model formulated in the form of eq. (8) in several possible ways. We chose the molar fraction of $\mathrm{CO}$ after the methanol condensation, $y^{*}$, to be the response and the reactor pressure, the temperature, the inlet molar fraction $\mathrm{CO}$ and the inlet flow to be the independent variables.

So $y=\left(y^{*}\right)$ and $\mathbf{x}=\left(P, T, y_{\mathrm{co}, \mathrm{in}}, F_{\text {in }}\right)$. Note that this is a single response model. This way of describing our system contrasts to the view of Villa et al. (1985). To clarify this controversy first we have to note that they had added an inert helium and were forced to deal with the water gas shift reaction (2) as well, because $\mathrm{CO}_{2}$ was present in their feed gases. They described their system with seven equations, two for the reactions (1) and (2) and five mass balances. They argued that all six mole fractions in the outlet, $y_{\mathrm{CO}}, y_{\mathrm{CO}_{2}}, y_{\mathrm{M}}$,
$y_{\mathrm{H}_{2}}, y_{\mathrm{H}_{2} \mathrm{O}}$ and $y_{\mathrm{He}}$, and the outlet flow have to be considered as model responses. However, we believe that from a physical point of view this is not correct. Physically for Villa et al. it was not a seven but a two dimensional problem as only two reactions were involved. By taking for instance the outlet flow or the mole fraction of inert helium in the outlet as an additional response, we would also be fitting the massbalance with kinetic parameters! Thus, in our system we only have to deal with one reaction and consequently only one model response must be chosen, e.g. $y^{*}$.

\section{EXPERIMENTAL PART}

The experimental set-up

The experimental set-up for the kinetic measurements is shown schematically in Fig. 3. The reactants $\mathrm{CO}$ and $\mathrm{H}_{2}$ were supplied from bottles and-after pressure reducing - set at the desired flow rates by means of two mass flow controllers of Brooks, type $5850 T R C$ and calibrated for $1.0 \mathrm{nl} / \mathrm{min} \mathrm{CO}$ and 2.0 $\mathrm{nl} / \mathrm{min} \mathrm{H}_{2}$ respectively. After that, the two streams were mixed. In this way synthesis gases with widely varying compositions could be produced. The synthesis gas was fed into the internal recycle reactor depicted in Fig. 2. The basket inside the reactor could be filled with at most $\pm 100 \mathrm{~g}$ of catalyst. In the experiments performed only about $10 \mathrm{~g}$ of catalyst was used, which roughly corresponded to one layer of catalyst pellets. The rotation speed of the impeller could be controlled by means of an electronic frequency controller manufactured by Microsyn, type 3005 , the maximum impeller speed being 55 r.p.s. The temperature of the reactor was regulated by an Eurotherm temperature controller. The control temperature was measured with a thermocouple installed in the insulation and near the heating oven. The temperature within the reactor was measured by $\mathbf{a}$ Ktype thermocouple with the weld located in the gas phase right above the catalyst bed. For a few of the experiments, the catalyst temperature was measured too. To this end, a catalyst particle from the catalyst bed was attached firmly to an additional K-type thermocouple with the weld in the centre of the particle. The reactor pressure was measured and controlled by an electronic back-pressure regulator manufactured by $\mathrm{Hi}-\mathrm{Tec}$, type $712 \mathrm{EC}$.

The product gas from the reactor outlet was led to a small cold trap vessel in which the methanol produced was condensed. With a ball valve and an additional needle valve the liquid methanol could be tapped. To prevent premature methanol condensation, the ball valve and the piping in between the reactor and the cold trap vessel were heated externally to approximately $450 \mathrm{~K}$. This high temperature was necessary because the methanol partial pressurc in the product gas could amount up to $2 \mathrm{MPa}$

Then the gas stream-after passing the back-pressure controller-was expanded to near atmospheric pressure. Via a rotameter, the gas could either be purged directly or led to a wet gas meter for the 

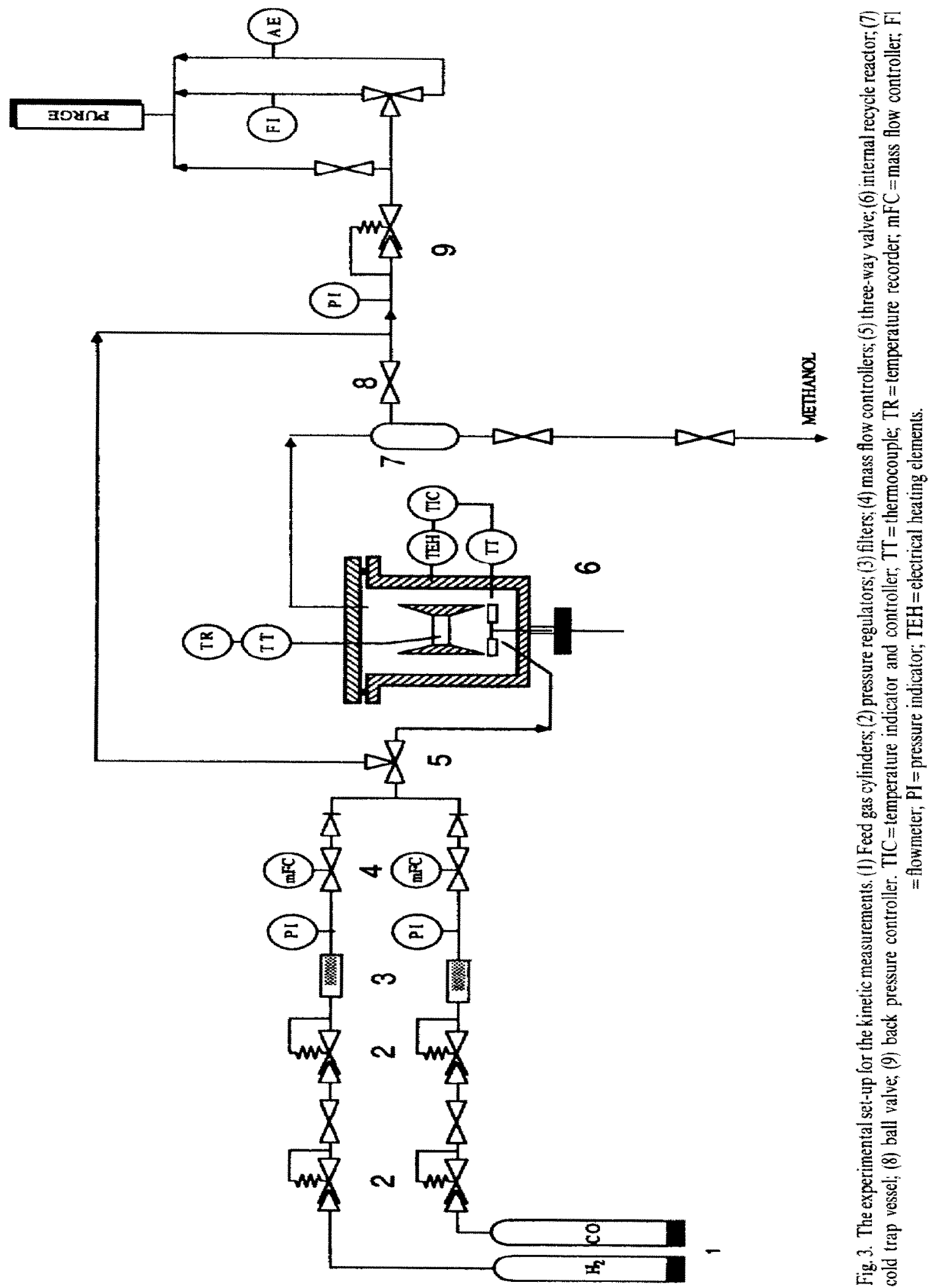
measuring of the volumetric flow or to an on-line gas chromatograph. The gas chromatograph of Varian, model 3770 , was equipped with a thermal conductivity detector, a $2 \mathrm{~m}$ long $1 / 8^{\prime \prime}$ diameter Porapack $\mathrm{Q}$ column, a Hewlett-Packard 3390-A programmable integrator, and a peristaltic pump coupled to a pneumatic sampling valve. Hydrogen was used as a carrier gas and the detector response was found to be linear with the $\mathrm{CO}$ content in the gas mixture. The mass flow controllers were found to be adequate for maintaining a constant flow rate, but could not be used for an accurate flow measurement. For the determination of the volumetric flow rate and composition of the feed gas it was possible to by-pass the reactor and lead the synthesis gas directly-via the back-pressure controller-to the wet gas meter and the gas chromatograph.

Some preliminary residence time distribution experiments were performed with basically the same set-up. Hеге the reactor feed could be switched from pure $\mathbf{H}_{2}$ to a $90 \% \mathrm{H}_{2} / 10 \% \mathrm{~N}_{2}$ mixture and vice versa by means of a manually operated four-way valve. A katharometer was used to record the breakthrough curves. During these experiments the basket inside the reactor was filled with $49.8 \mathrm{~g}$ non-activated catalyst.

\section{The experimental procedure}

After filling the basket with an accurately weighed amount of catalyst it was placed inside the reactor. The reactor was tested for leaks by filling it with pure hydrogen up to $8 \mathrm{MPa}$ and observing the pressure decrease in time. The catalyst was then activated by reduction according to the procedure prescribed by the supplier (BASF, 1979) and briefly outlined in a previous paper (Kuczynski et al., 1987a). After this activation the catalyst activity was not yet constant, therefore, the kinetic experiments were started only after $72 \mathrm{~h}$ on stream. During this period the catalyst activity was monitored in time and checked on constancy by measuring the amount of methanol tapped from the cold trap vessel. Overnight and during all other temporary shut-downs of the installation, the catalyst was kept at $0.4 \mathrm{MPa}$ and $470 \mathrm{~K}$ nitrogen.

The kinetic experiments were executed according to the following procedure. First the reactor was fed with hydrogen only. Meanwhile the temperature was raised corresponding to the desired value for the forthcoming experiment. The impeller speed usually was set at 30 r.p.s. since at higher speeds the construction was rather trouble prone, particularly the bearings.

The reactor pressure was raised, the feed still being only $\mathbf{H}_{2}$. After the desired pressure was reached, we started the procedure for the determination of the flow and the composition of the feed gas. First the reactor was by-passed by switching three-way valve 5 and - to prevent gas leaking into or out of the reactor-closing valve 8 . The hydrogen flow was set to the desired value by means of the mass flow controller and measured with the wet gas meter. Then carbon monoxide with the desired flow rate was added to the hydrogen. The total flow was measured with the wet gas meter and the composition of the mixture determined by means of an analysis with the gas chromatograph. Usually a total of five samples of this synthesis gas was taken for the analysis.

The reactor was switched on stream again by opening valve 8 and switching three-way valve 5 . Then a series of experiments could be started. The product gas composition was monitored in time and a steady state was reached typically after $1.5 \mathrm{~h}$. The product gas flow and composition were then determined and the reactor pressure and temperature of this experimental run registered. Hereafter methanol was tapped from the cold trap vessel and a new experiment could be started by setting a new temperature without changing the feed gas flow and composition. In this way a series of experiments could be performed efficiently. Only a few times was a new total pressure set, but we never adjusted the mass flow controllers within one and the same series of experiments, for this would introduce an unnecessary inaccuracy in the inlet flow. A series of experiments was ended by replacing the $\mathrm{CO}$ and $\mathrm{H}_{2}$ flow with a nitrogen flow, and reducing the reactor pressure to $0.4 \mathrm{MPa}$ and the temperature to $470 \mathrm{~K}$.

\section{Accuracy of the experiments}

The maximum relative error in the gas chromatographic analysis was $1 \%$. The estimated crror in the pressure measurements was $0.02 \mathrm{MPa}$. For the relative high flow rate of $1-2 \mathrm{nl} / \mathrm{min}$ the volumetric flow measurement was believed to be rather accurate with $0.5 \%$ error. For lower flows we had to account for errors up to $2 \%$. These errors were of the same order of magnitude as in our previous study (Kuczynski et al., 1987a).

\section{RESULTS AND DISCUSSION}

\section{Residence time distribution experiments}

Prior to undertaking the kinetic measurements a total of 35 residence time distribution (RTD) experiments were performed. No useful experiments could be performed at pressures higher than $0.5 \mathrm{MPa}$. At these higher pressures the switching of the four-way valve initiated a notable pressure surge. Combined with the controlling characteristics of the back pressure controller, this caused severe deviations in the outlet flow and therefore a falsification of the RTD experiment.

Ambient temperatures and moderate flows of around $0.5 \mathrm{nl} / \mathrm{min}$ were employed. The impeller rotation speed, whose influence was of our main interest, was varied over the entire possible range of $0-55$ r.p.s.

With the set-up described before $F(t)$ curves were obtained. For mixtures of nitrogen and hydrogen in the range of 90 to $100 \% \mathrm{H}_{2}$, the thermal conductivity was found to be linear with the $\mathrm{H}_{2}$ fraction and, therefore, the normalized response from the katharometer, $U(t) / U(t=\infty)$ or $1-U(t) / U(t=0)$, equals $F(t)$. 
A typical plot of the function $F(t)$ as obtained experimentally is shown in Fig. 4(a) and the corresponding plot of $-\ln (1-F(t))$ in Fig. $4(b)$. From the linearity of the latter plots we concluded that serious deviations from perfect mixing on a macroscale occur only in case of very low impeller speeds of below 10 r.p.s. The sigmoid shape of the $F(t)$ curves was attributed to the non-ideality of the input step-function and to axial dispersion in the piping system to and in the katharometer. The latter could not be fully neglected as followed from the calculations made with the Badenstein correlation recommended by Westerterp et al. (1984).

\section{Kinetic experiments}

After several initial and serious problems related to the complex and delicate design of the reactor, a total of 45 kinetic experiments were performed and evaluated. The data of these experiments are given in Table 2. The feed gas composition varied from 6 to $24 \%$ carbon monoxide, the balance being only $\mathrm{H}_{2}$. Reactor pressures of 3 to $7 \mathrm{MPa}$ and temperatures of 490-550 K were applied.

We have assumed that heat and mass transfer limitations, internal as well as external, were absent. Partly this was based on calculations made by other authors (Villa et al., 1985; Seyfert and Luft, 1985) for more critical conditions in absence of $\mathrm{CO}_{2}$ and consequently at much higher reaction rates. However, the estimates of the external resistances depend strongly
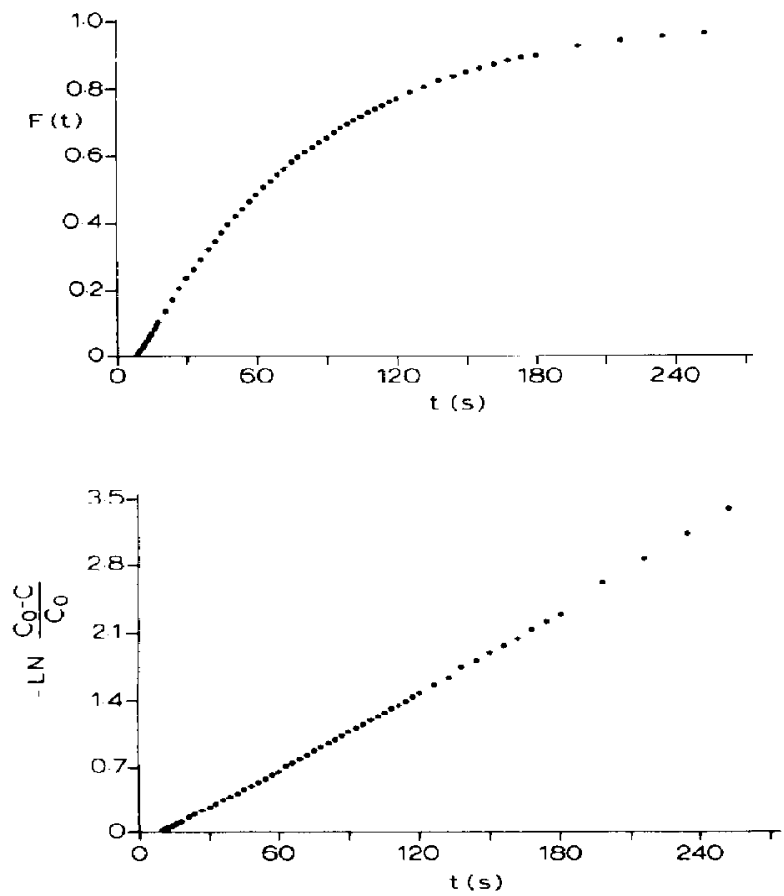

Fig. 4. A typical result of the RTD experiments. The impeller speed 20 r.p.s. (a) An experimentally obtained $F(t)$-curve; (b) $-\ln (1-(F(t))$ vs time. on the actual gas velocity over the catalyst bed. Therefore in a Berty type reactor these estimates are also highly dependent on the estimate of the recycle ratio $R$, which determines the actual gas velocity $v_{\mathrm{g}}$. As mentioned before, a conventional method for the determination of $R$ such as applied by Villa et al. is rather inaccurate. So, we have to take into account the uncertainty of the value of the recycle ratio from which $v_{\mathrm{g}}$ is calculated, as well as the inaccuracies in the correlations by which $k_{\mathrm{g}}$ and $x_{\mathrm{p}}$ are calculated from this $v_{\mathrm{g}}$. Therefore we believe the estimates of the resistances to be highly inaccurate and abstain from presenting them.

Further indications that the heat and mass transfer limitations are negligible were obtained experimentally. Variation of the impeller speed over a wide range did not have a detectable effect on the conversion, except at very low speeds where the assumption of perfect mixing is no longer valid. Some more information was obtained in the experiments in which we measured both the gas phase and the catalyst temperature: for the most severe conditions applied, i.e. at the highest rate of reaction, the temperature difference between the gas and solid phase did not exceed $1.5 \mathrm{~K}$, except at very low impeller speeds for which we measured temperature differences of up to $20 \mathrm{~K}$.

If our assumptions hold true the experimental conversion rate $R_{\mathrm{CO}}$ can be calculated from:

$$
\boldsymbol{R}_{\mathrm{CO}}=\frac{y_{\mathrm{CO} . \mathrm{in}} \boldsymbol{F}_{\mathrm{in}}}{W} \zeta
$$

where by definition

$$
\zeta=\frac{F_{\mathrm{Co} . \text { in }}-F_{\mathrm{co}, \mathrm{out}}}{F_{\mathrm{CO}, \mathrm{in}}} .
$$

We assumed that side and consecutive reactions were negligible, which can be checked by the experimental data given in Table 3 where a typical product gas composition is presented. Since all methanol was condensed in the cold trap vessel, the experimental conversion $\zeta$ can be calculated from:

$$
\zeta=\frac{y_{\mathrm{CO}, \mathrm{in}}-y^{*}}{y_{\mathrm{CO}, \mathrm{in}}-3 y_{\mathrm{CO}, \mathrm{in}} y^{*}}
$$

in which $y^{*}$ is the molar fraction $\mathrm{CO}$ after the methanol condensation. From this equation it can be seen that with our set-up it was not useful to perform kinetic measurements near stoichiometric feed gas compositions. If $y_{C O, \text { in }} \approx 0.33$ then also $y^{*} \approx 0.33$ and the denominator of eq. (11) is almost equal to zero resulting in very large errors in $\zeta$ due to errors in $y^{*}$. Therefore we limited our experimental range to $6-24 \% \mathrm{CO}$ in the feed gas. We further neglected the amount of $\mathrm{CO}$ and $\mathrm{H}_{2}$ dissolved in the liquid methanol condensed in the cold trap vessel. On the basis of data taken from Stephen and Stephen (1963), we calculated that in our experiments the methanol contained at most $0.009 \mathrm{~mol} \mathrm{H}_{2}$ and $0.020 \mathrm{~mol} \mathrm{CO}$ per mole $\mathrm{CH}_{3} \mathrm{OH}$ condensed. $\mathrm{CO}$ dissolves better than $\mathrm{H}_{2}$, which implies that a slight overestimation of our 
A. N. R. Bos et al.

Table 2. The experimental data

\begin{tabular}{|c|c|c|c|c|c|c|c|c|c|c|c|}
\hline Run & $\begin{array}{c}T \\
(\mathbf{K})\end{array}$ & $\begin{array}{c}P \\
(0.1 \mathrm{MPa})\end{array}$ & $y_{\mathrm{Co}, \text { in }}$ & $\left.\underset{(\text { nl min }}{F_{\text {in }}}-1\right)$ & $y^{*}$ & $\begin{array}{c}F_{\text {aut }} \\
\left(\text { nl } \text { min }^{-1}\right)\end{array}$ & $y_{\mathrm{CO}}$ & $y_{\mathbf{H}_{2}}$ & $y_{M}$ & $\zeta$ & 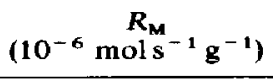 \\
\hline 1 & 513 & 60.0 & 0.152 & 0.923 & 0.134 & 0.856 & 0.130 & 0.838 & 0.032 & 0.20 & 1.8 \\
\hline 2 & 525 & 60.0 & 0.152 & 0.923 & 0.129 & 0.831 & 0.123 & 0.835 & 0.042 & 0.25 & 2.2 \\
\hline 3 & 534 & 60.0 & 0.152 & 0.923 & 0.121 & 0.808 & 0.115 & 0.831 & 0.054 & 0.32 & 2.8 \\
\hline 4 & 524 & 50.1 & 0.106 & 0.876 & 0.082 & 0.808 & 0.080 & 0.887 & 0.033 & 0.29 & 1.3 \\
\hline 5 & 535 & 50.1 & 0.106 & 0.876 & 0.079 & 0.794 & 0.076 & 0.886 & 0.037 & 0.33 & 1.4 \\
\hline 6 & 541 & 50.1 & 0.106 & 0.876 & 0.076 & 0.792 & 0.073 & 0.886 & 0.042 & 0.36 & 1.6 \\
\hline 7 & 543 & 50.1 & 0.106 & 0.876 & 0.076 & 0.790 & 0.072 & 0.886 & 0.042 & 0.37 & 1.6 \\
\hline 8 & 505 & 70.3 & 0.241 & 0.980 & 0.233 & 0.899 & 0.227 & 0.747 & 0.026 & 0.10 & 1.6 \\
\hline 9 & 509 & 70.3 & 0.241 & 0.980 & 0.232 & 0.886 & 0.225 & 0.745 & 0.030 & 0.12 & 1.8 \\
\hline 10 & 526 & 70.3 & 0.241 & 0.980 & 0.229 & 0.846 & 0.220 & 0.741 & 0.039 & 0.15 & 2.3 \\
\hline 11 & 535 & 70.3 & 0.241 & 0.980 & 0.223 & 0.808 & 0.210 & 0.731 & 0.059 & 0.22 & 3.4 \\
\hline 12 & 507 & 65.2 & 0.188 & 0.954 & 0.172 & 0.895 & 0.166 & 0.799 & 0.034 & 0.17 & 1.7 \\
\hline 13 & 514 & 65.2 & 0.188 & 0.954 & 0.171 & 0.876 & 0.165 & 0.799 & 0.036 & 0.18 & 1.8 \\
\hline 14 & 516 & 50.0 & 0.188 & 0.954 & 0.177 & 0.900 & 0.173 & 0.803 & 0.024 & 0.12 & 1. 2 \\
\hline 15 & 530 & 50.0 & 0.188 & 0.954 & 0.169 & 0.868 & 0.163 & 0.797 & 0.040 & 0.20 & 2.0 \\
\hline 16 & 541 & 50.0 & 0.188 & 0.954 & 0.165 & 0.844 & 0.156 & 0.793 & 0.050 & 0.24 & 2.5 \\
\hline 17 & 514 & 60.4 & 0.146 & 0.951 & 0.130 & 0.903 & 0.126 & 0.845 & 0.029 & 0.19 & 1.4 \\
\hline 18 & 514 & 50.4 & 0.146 & 0.951 & 0.133 & 0.907 & 0.129 & 0.847 & 0.024 & 0.15 & 1.1 \\
\hline 19 & 514 & 40.4 & 0.146 & 0.951 & 0.136 & 0.928 & 0.133 & 0.850 & 0.018 & 0.12 & 0.9 \\
\hline 20 & 514 & 30.3 & 0.146 & 0.951 & 0.139 & 0.944 & 0.137 & 0.849 & 0.012 & 0.08 & 0.6 \\
\hline 21 & 523 & 30.3 & 0.146 & 0.951 & 0.137 & 0.936 & 0.134 & 0.849 & 0.017 & 0.11 & 0.8 \\
\hline 22 & 523 & 50.4 & 0.146 & 0.949 & 0.127 & 0.899 & 0.123 & 0.844 & 0.032 & 0.21 & 1.5 \\
\hline 23 & 524 & 60.5 & 0.146 & 0.951 & 0.122 & 0.876 & 0.117 & 0.842 & 0.041 & 0.26 & 1.9 \\
\hline 24 & 524 & 70.4 & 0.146 & 0.951 & 0.118 & 0.866 & 0.113 & 0.840 & 0.048 & 0.30 & 2.2 \\
\hline 25 & 533 & 70.4 & 0.146 & 0.951 & 0.111 & 0.840 & 0.105 & 0.837 & 0.058 & 0.36 & 2.6 \\
\hline 26 & 511 & 70.4 & 0.067 & 1.489 & 0.052 & 1.427 & 0.051 & 0.931 & 0.018 & 0.26 & 1.7 \\
\hline 27 & 525 & 70.4 & 0.067 & 1.489 & 0.048 & 1.411 & 0.047 & 0.930 & 0.023 & 0.33 & 2.1 \\
\hline 28 & 535 & 70.4 & 0.067 & 1.489 & 0.045 & 1.400 & 0.044 & 0.930 & 0.027 & 0.38 & 2.4 \\
\hline 29 & 543 & 70.4 & 0.067 & 1.489 & 0.042 & 1.389 & 0.041 & 0.929 & 0.029 & 0.42 & 2.6 \\
\hline 30 & 521 & 60.5 & 0.063 & 1.484 & 0.048 & 1.393 & 0.047 & 0.935 & 0.018 & 0.27 & 1.8 \\
\hline 31 & 532 & 60.5 & 0.063 & 1.484 & 0.045 & 1.406 & 0.045 & 0.935 & 0.021 & 0.32 & 2.0 \\
\hline 32 & 538 & 60.5 & 0.063 & 1.484 & 0.044 & 1.407 & 0.043 & 0.935 & 0.022 & 0.34 & 2.2 \\
\hline 33 & 518 & 60.4 & 0.061 & 1.471 & 0.048 & 1.418 & 0.047 & 0.937 & 0.017 & 0.26 & 1.6 \\
\hline 34 & 528 & 60.4 & 0.061 & 1.471 & 0.047 & 1.424 & 0.046 & 0.936 & 0.017 & 0.28 & 1.7 \\
\hline 35 & 540 & 60.4 & 0.061 & 1.471 & 0.044 & 1.402 & 0.043 & 0.936 & 0.021 & 0.32 & 2.0 \\
\hline 36 & 522 & 50.4 & 0.063 & 1.480 & 0.051 & 1.443 & 0.050 & 0.935 & 0.015 & 0.23 & 1.5 \\
\hline 37 & 532 & 50.4 & 0.063 & 1.480 & 0.050 & 1.443 & 0.049 & 0.935 & 0.017 & 0.25 & 1.6 \\
\hline 38 & 543 & 50.4 & 0.063 & 1.480 & 0.048 & 1.443 & 0.048 & 0.934 & 0.018 & 0.28 & 1.8 \\
\hline 40 & 518 & 60.4 & 0.128 & 1.568 & 0.115 & 1.533 & 0.113 & 0.867 & 0.020 & 0.15 & 2.1 \\
\hline 41 & 530 & 60.4 & 0.128 & 1.568 & 0.110 & 1.494 & 0.107 & 0.866 & 0.027 & 0.20 & 2.8 \\
\hline 42 & 541 & 60.5 & 0.128 & 1.568 & 0.106 & 1.476 & 0.103 & 0.864 & 0.033 & 0.24 & 3.3 \\
\hline 43 & 541 & 50.5 & 0.128 & 1.568 & 0.112 & 1.501 & 0.109 & 0.866 & 0.024 & 0.18 & 2.5 \\
\hline 44 & 521 & 70.5 & 0.137 & 0.676 & 0.097 & 0.585 & 0.091 & 0.846 & 0.063 & 0.41 & 2.6 \\
\hline 45 & 532 & 70.5 & 0.137 & 0.676 & 0.093 & 0.567 & 0.086 & 0.844 & 0.069 & 0.44 & 2.8 \\
\hline
\end{tabular}

experimental rate of reaction may have occurred, specially for those experiments at the highest pressure taken and with high $\mathrm{CO}$ contents. On the average we feel that we correctly neglected this effect of dissolution of gases in the methanol.

For our system we now have the equation:

$$
\boldsymbol{R}_{\operatorname{mode1}}-\boldsymbol{R}_{\text {exp }}=0
$$

where $R_{\text {model }}=R_{\text {Co }}\left(P, T, y_{\mathrm{CO}}, y_{\mathrm{H}_{2}}, y_{\mathrm{M}}, \theta\right)$ e.g. an equation from Table 1 -and further $R_{\text {exp }}=y_{\text {Co,in }} F_{\text {in }} \zeta / W$. The conversion $\zeta$ can be calculated from $y^{*}$ with eq. (11), and from this $\zeta$ we can obtain values for $y_{\mathrm{CO}}, y_{\mathrm{H}_{2}}$ and $y_{M}$ with:

$$
\begin{aligned}
& y_{\mathrm{CO}}=\frac{y_{\mathrm{CO}, \mathrm{in}}(1-\zeta)}{1-2 y_{\mathrm{CO}, \mathrm{in}} \zeta} \\
& y_{\mathrm{H}_{2}}=\frac{y_{\mathrm{H}_{2, \mathrm{in}}}-2 y_{\mathrm{CO}, \mathrm{in} \zeta}}{1-2 y_{\mathrm{CO}, \mathrm{in}} \zeta}
\end{aligned}
$$

Table 3. Two typical product gas compositions as obtained after methanol condensation in the cold trap vessel

\begin{tabular}{lcc}
\hline & $\begin{array}{c}\text { Low conversion } \\
(\%)\end{array}$ & $\begin{array}{c}\text { High conversion } \\
(\%)\end{array}$ \\
\hline $\mathrm{H}_{2}$ & 88.5 & 91.1 \\
$\mathrm{CO}$ & 11.5 & 8.6 \\
$\mathrm{CO}$ & $<0.02$ & 0.1 \\
$\mathrm{CH}_{3} \mathrm{OH}$ & $<0.01$ & 0.08 \\
$\mathrm{CH}_{4}$ & $<0.01$ & 0.03 \\
$\left(\mathrm{CH}_{3}\right)_{2} \mathrm{OH}$ & $<0.01$ & $<0.01$ \\
\hline
\end{tabular}

$$
y_{M}=\frac{y_{C O, \text { in }} \zeta}{1-2 y_{C O, i n} \zeta} .
$$

It is important to note that eq. (12) is the model formulation in the form of eq. (8). It is needed in this form for the RKPES parameter estimation program. 
It is an implicit equation which has to be solved numerically with respect to $y^{*}$, the molar fraction $\mathrm{CO}$ after methanol condensation. This calculation was incorporated in the RKPES model subroutine, which calculates $y^{*}$ from the independent variables.

The fugacities divided by the standard-state pressure $P^{\circ}=0.1 \mathrm{MPa}$ can be expressed as $\phi_{\mathrm{i}}=y_{\mathrm{i}} P_{\mathrm{T}} f_{\mathrm{i}} / P^{\circ}$. The fugacity coefficients $f_{i}$ were calculated in each iteration step of the optimization procedure with expressions derived from the Peng-Robinson equation of state (Peng and Robinson, 1976). We have described this in more detail previously (Kuczynski et al., 1987a).

For the equilibrium constant $K_{\mathrm{eq}}$ of reaction (1) the following correlation can be derived (Kuczynski et al., 1987a):

$$
\ln K_{\text {eq }}=-28.9762+11,815 / T \text {. }
$$

All parameters in the kinetic models were assumed to be of the Arrhenius type. In order to increase convergence they were reparameterized into:

$$
K_{\mathrm{i}}=\exp \left(K_{\mathrm{io}}-\frac{K_{\mathrm{ia}}}{R}(1 / T-1 / \bar{T})\right)
$$

where $\bar{T}$ is a reference temperature taken equal to $523 \mathrm{~K}$. The parameter $K_{\text {ia }}$ is either an activation energy, an adsorption enthalpy or a lumping of both.

We have tried to fit rate equations from Kuczynski et al. (1987a) and from Table 1. For discrimination between the models the following criteria were considered:

(1) the value $\Sigma$ of the sum of squares of the residuals at the optimum
(2) the $T$-values, being the ratio of the calculated parameter values to their standard deviations and (3) the randomness of the distribution of the residuals.

For most models extremely poor fits were obtained. In Table 4 the rate expressions that appeared to fit the experiments best are presented with their parameter values, $\Sigma$ - and $T$-values. In Fig. 5 the corresponding distribution of the residuals is plotted. The $T$-values are compared to our previous results relatively well. However, these values should be treated carefully and certainly cannot be used as the sole discriminator. Note the influence of the reparameterization and furthermore that $T$-values tend to decrease with an increasing number of parameters. The $T$-values of the activation energies are low, conform their reputation. As can be seen from Table 4 we have deleted the methanol absorption terms, which always turned out to be negligible.

From the residual plots shown in Fig. 5, for the rate expressions $R_{1}, R_{4}, R_{7}$ and $R_{12}$ from Table 4 respectively - which fit the data best - the goodness of fit can be seen. These plots contain the same information as obtained from the commonly used plots of the experimental response against the model response, but with this method of presentation also the randomness of the distribution of the error can be inspected. For the simple model 12 , for which extremely good $T$-values were obtained, clearly the error distribution is not random and therefore this expression appears to be less appropriate.

Compared to our previous results (Kuczynski et al., 1987a) somewhat higher reaction rates were found, but they were still much lower than those reported by

\begin{tabular}{|c|c|c|c|c|c|}
\hline Model & Parameter $^{\dagger}$ & Parameter value & $T$-value & $\Sigma / n \times 10^{5}$ & Rate expression \\
\hline \multirow[t]{6}{*}{1} & $K_{r-\alpha}$ & -2.65 & 17.5 & \multirow{6}{*}{0.19} & $R_{1}=K_{\mathrm{r}} K_{\mathrm{CO}} K_{\mathrm{H}_{2}}^{2}\left(\phi_{\mathrm{CO}} \phi_{\mathrm{H}_{2}}^{2}-\phi_{\mathrm{M}} / K_{\mathrm{cq}}\right)$ \\
\hline & $K_{r, a}^{r, 0}$ & $26.9 \times 10^{3}$ & 0.8 & & $\left(1+K_{\mathrm{CO}} \phi_{\mathrm{CO}}+K_{\mathrm{H}_{2}} \phi_{\mathrm{H}_{2}}\right)^{3}$ \\
\hline & $K_{\text {Co.0 }}$ & -2.37 & 19.6 & & \\
\hline & $K_{\text {Co.a }}$ & $28.5 \times 10^{3}$ & 1.0 & & \\
\hline & $K_{\mathrm{H}_{2,0}}$ & -3.87 & 25.6 & & \\
\hline & $K_{\mathrm{H}_{2}, \mathbf{a}}$ & $38.6 \times 10^{3}$ & 1.2 & & \\
\hline \multirow{6}{*}{4} & $K_{r, 0}$ & -14.7 & 113.1 & \multirow{6}{*}{0.27} & $K_{\mathrm{r}}\left(\phi_{\mathrm{CO}} \phi_{\mathrm{H}_{2}}^{2}-\phi_{\mathrm{M}} / K_{\mathrm{eq}}\right)$ \\
\hline & $K_{r, a}$ & $86.0 \times 10^{3}$ & 3.5 & & $\left(1+K_{\mathrm{CO}} \phi_{\mathrm{co}}+K_{\mathbf{H}_{2}} \phi_{\mathrm{H}_{2}}^{2} \phi_{\mathrm{CO}}\right)$ \\
\hline & $K_{\mathrm{CO} . \mathrm{o}}$ & -4.74 & 1.1 & & \\
\hline & $K_{\mathrm{CO}, \mathrm{a}}$ & $-143.0 \times 10^{3}$ & 0.3 & & \\
\hline & $\boldsymbol{K}_{\mathbf{H}_{2,0}}$ & -9.13 & 60.9 & & \\
\hline & $\kappa_{\mathbf{H}_{2, \mathbf{a}}}$ & $39.0 \times 10^{-}$ & 1.0 & & $K\left(\phi_{c o} \phi_{u}^{2}-\phi_{\mathrm{w}} / K\right.$ \\
\hline \multirow[t]{5}{*}{7} & $K_{\mathrm{r}, \mathrm{o}}$ & -10.6 & 62.3 & \multirow[t]{5}{*}{0.20} & $\mathrm{~A}_{\mathrm{r}}\left(\varphi_{\mathrm{CO}} \varphi_{\overline{\mathrm{H}}_{2}}-\varphi_{\mathrm{M}} / \mathrm{\Lambda}_{\mathrm{eq}}\right)$ \\
\hline & $K_{\mathrm{r}, \mathbf{a}}$ & $98.6 \times 10^{3}$ & 3.0 & & $\phi_{\mathrm{H}_{2}}\left(1+K_{\mathrm{CO}} \phi_{\mathrm{CO}}+K_{\mathrm{H}_{2}} \phi_{\mathrm{H}_{2}}\right)^{2}$ \\
\hline & $K_{\text {co,o }}$ & -2.35 & 19.1 & & \\
\hline & $K_{\mathrm{CO} . \mathrm{a}}$ & $23.1 \times 10^{3}$ & 0.9 & & \\
\hline & $K_{\mathbf{H}_{2+0}}$ & $67.7 \times 10^{3}$ & $\begin{array}{r}13.0 \\
1.2\end{array}$ & & \\
\hline \multirow[b]{2}{*}{12} & & & & \multirow[b]{2}{*}{2.2} & $K_{r}\left(\phi_{\mathrm{CO}} \phi_{\mathrm{H}_{2}}^{2}-\phi_{\mathrm{M}} / K_{\mathrm{eq}}\right)$ \\
\hline & $\begin{array}{l}K_{\text {r.o }} \\
K_{r . a}\end{array}$ & $\begin{aligned}-11.9 \\
93.9 \times 10^{3}\end{aligned}$ & $\begin{array}{r}224.0 \\
81.0\end{array}$ & & $R_{12}=\frac{\phi_{\mathrm{H}_{2}}}{\phi_{1}}$ \\
\hline
\end{tabular}

Table 4. The fitted rate expressions with their parameter, $T$ - and $\Sigma$-values

+Note that the parameters are reparameterized according to eq. (17). 
A. N. R. Bos et al.

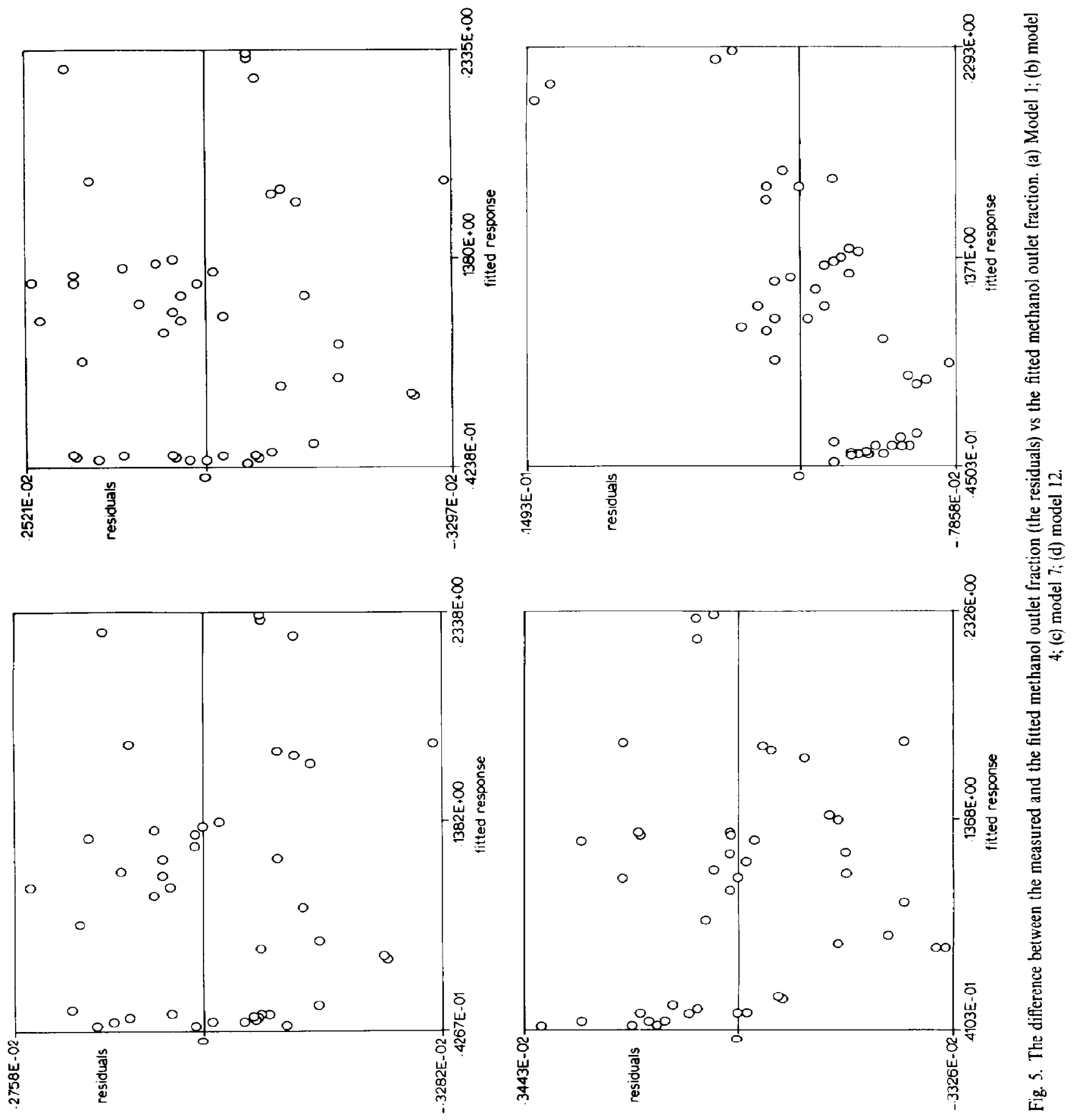


other authors for $\mathrm{CO}_{2}$-containing feed gases. This is illustrated in Fig. 6, where we present Arrhenius plots of our models $1,4,7$ and 12 and the expression proposed by Seyfert and Luft (1985). These plots also reveal that for conditions corresponding to our experiments, the models 1,4 and 7 coincide almost perfectly and model 12 to a lesser extent. However, outside the experimental range appreciable differences in reaction rates calculated from these 4 models are found. From Fig. 6 it can be observed that the overall temperature sensitivity of the Seyfert and Luft kinetics (1985) is much larger than in our experiments. The correlation of Seyfert and Luft has been extrapolated by us to reaction mixtures without $\mathrm{CO}_{2}$; however in their experiments $\mathrm{CO}_{2}$ was always present. It should be noted that their expression is based upon a retarding effect of $\mathrm{CO}_{2}$ on the reaction rate.

The rate expressions we previously proposed describe the current experiments rather poorly, confirming the doubts we put forward in that study, because the integral tubular reactor as used there could not be kept isothermal. This difference between the two experimental studies also indicates an obvious but sometimes not fully recognized aspect of kinetic studies of heterogeneously catalyzed reactions: the activity can vary strongly not only between catalysts from different suppliers or different batches, but also for the different pellets from one single batch. Therefore-and this generally holds true for heterogeneously catalyzed reactions - it has to be anticipated that the experimentally determined kinetic expres-

$$
\begin{array}{ll}
\mathrm{CO}+3 \mathrm{H}_{2}=\mathrm{CH}_{4}+\mathrm{H}_{2} \mathrm{O} & \Delta H_{298 \mathrm{k}}=-206 \mathrm{~kJ} \mathrm{~mol}^{-1} \\
2 \mathrm{CO}+2 \mathrm{H}_{2}=\mathrm{CH}_{4}+\mathrm{CO}_{2} & \Delta H_{298 \mathrm{k}}=-247 \mathrm{~kJ} \mathrm{~mol}^{-1} \\
2 \mathrm{CH} \mathrm{OH}_{3}=\left(\mathrm{CH}_{3}\right)_{2} \mathrm{O}+\mathrm{H}_{2} \mathrm{O} & \Delta H_{298 \mathrm{k}}=-23.5 \mathrm{~kJ} \mathrm{~mol}^{-1} \\
2 \mathrm{CO}+4 \mathrm{H}_{2}=\left(\mathrm{CH}_{3}\right)_{2} \mathrm{O}+\mathrm{H}_{2} \mathrm{O} & \Delta H_{298 \mathrm{~K}}=-206 \mathrm{~kJ} \mathrm{~mol}^{-1}
\end{array}
$$

sions have a rather limited value only and need a recalibration at least for every new batch.

The fits obtained from the experiments in the internal recycle reactor were better than those obtained in the quasi isothermal tubular reactor. However, the fits are still not fully satisfactory. No single reaction rate equation could be selected as the best. Much less can be said on the possible mechanism of the reaction, even if only one single rate expression-derived from a certain mechanism - fits the data well. Evidence on the mechanism can only be given by other techniques, e.g. a surface technique. So, we abstain from the common linking of the equations obtained to their "corresponding" mechanism. Keeping this in mind, we will take a closer look at the values of the parameters $K_{\text {ia }}$. In a Langmuir-Hinshelwood model these would be interpreted in terms of adsorption enthalpies. As positive adsorption enthalpies are physically irrealistic a number of the $K_{\mathrm{ia}}$-values obtained would be considered to be wrong. Other authors (Seyfert and Luft, 1985; Villa et al., 1987) also had to deal with this. We argue that, since we must not link our kinetic pressions back to mechanisms and merely regard be discarted on the basis of the $K_{i a}$-values.

For our present kinetic experiments, we believe that the strong promotional effect of small amounts of $\mathrm{H}_{2} \mathrm{O}$ and $\mathrm{CO}_{2}$ is the main cause for the relative unreliability of the rate expressions obtained. In our literature review we have pointed out some of the effects of $\mathrm{CO}_{2}$ and $\mathrm{H}_{2} \mathrm{O}$. Although our synthesis gas contained $\mathrm{CO}$ and $\mathrm{H}_{2}$ only, $\mathrm{CO}_{2}$ as well as $\mathrm{H}_{2} \mathrm{O}$ can be formed by side and consecutive reactions, e.g.
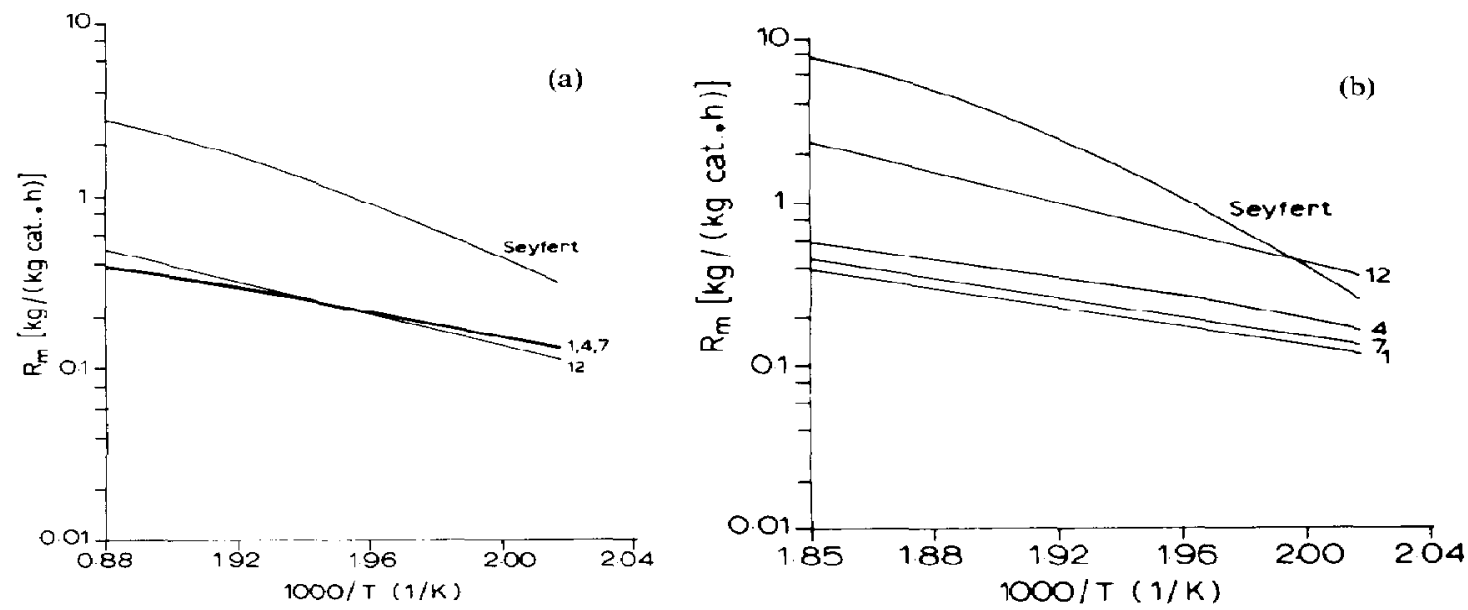

Fig. 6. Arrhenius plots of the rate expressions 1, 4, 7,12 and the expression proposed by Seyfert and Luft (1965). (a) $P=8.0 \mathrm{MPa}, y_{\mathrm{CO}}=0.33, y_{\mathrm{H}_{2}}=0.67, y_{\mathrm{M}}=y_{\mathrm{CO} 2}=0$. (b) $P=6.0 \mathrm{MPa}, y_{\mathrm{CO}}=0.15, y_{\mathrm{It} z}=0.85$, 
These side reactions are unimportant with respect to the selectivity of the methanol synthesis, but are known to accompany to some extent the main reaction of eq. (1). From the data given in Table 3 it can be seen that small amounts of $\mathrm{CO}_{2}$ indeed were present. The exact amount varied rather strongly with the reaction conditions and this could have caused strong variations in catalyst activity. Obviously, the normal Langmuir-Hinshelwood rate equations for reaction (1), which contain $\mathrm{CO}, \mathrm{H}_{2}$ and methanol terms only, are not able to take into account the $\mathrm{CO}_{2}$ and $\mathrm{H}_{2} \mathrm{O}$ effects. These appear to be of main importance, particularly in the lower $\mathrm{CO}_{2}$ and $\mathrm{H}_{2} \mathrm{O}$ range.

\section{CONCLUSIONS}

The residence time distribution experiments indicated that in our internal recycle reactor perfect mixing on a macro-scale could be assumed. From a construction point of view our reactor is rather delicate. It is possible to avoid the constructive difficulties with a larger reactor design. A larger reactor would have the additional advantage of a larger impeller diameter and consequently higher recycle ratios, for the head of the impeller is proportional to the fifth power of the impeller diameter. A major drawback in our opinion is the difficulty to obtain an accurate estimate of the crucial parameter $R$, the recycle ratio. A total 45 successful kinetic experiments have been performed. The catalyst proved to be highly selective and in contrast to what some other authors reported remained active for feed gases containing solely $\mathrm{CO}$ and $\mathrm{H}_{2}$.

We have fitted several rate equations. More accurate results and better fits than with the integral reactor (Kuczynski et al., 1987a) have been obtained. We could not select a single expression as the most appropriate one. The accuracy of the equations obtained was not fully satisfactory. We attributed this mainly to the strong promotional effects of $\mathrm{CO}_{2}$ and $\mathrm{H}_{2} \mathrm{O}$. We conclude that the simple Langmuir-Hinshelwood or Eley-Rideal rate expressions are not adequate to fescribe the methanol synthesis for $\mathrm{CO} / \mathrm{H}_{2}$ feed gases, due to the formation of small amounts of carbon dioxide and water, which are known to have a significant effect on the catalyst activity. So, the absence of $\mathrm{CO}_{2}$ and $\mathrm{H}_{2} \mathrm{O}$ in the feed gas does not decrease but increases the complexity of the reaction system. Therefore more effort should be put into clarifying the mechanism and the role of $\mathrm{CO}_{2}$ and $\mathrm{H}_{2} \mathrm{O}$. Only then a more reliable kinetic expression can be obtained for the synthesis of methanol from feed gases containing solely $\mathrm{CO}$ and $\mathrm{H}_{2}$. These expressions are likely to contain $\mathrm{CO}_{2}$ and $\mathrm{H}_{2} \mathrm{O}$ terms. This leads us to the important conclusion that, in a kinetic study of the synthesis of methanol, it is necessary to determine the $\mathrm{CO}_{2}$ and $\mathrm{H}_{2} \mathrm{O}$ content in the reaction mixtures accurately, even if $\mathrm{CO}_{2}$ and $\mathrm{H}_{2} \mathrm{O}$ are not present in the feed gas.

Acknowledgements-The authors wish to thank Twente University of Technology for the financial support. We appreci- ate the help of Prof. Dr Ing. G. Luft and Dr Ing. W. Seyfert of the T. H. Darmstadt who provided us with detailed information of their own work and Dr H. W. Schmidt of BASF Ludwigshafen who supplied the catalyst. We also thank Ir. H. J. Fontein for help with the statistical evaluation of the data and $A$. H. Pleiter and $K$. van Bree for their technical assistance. The first author, A. N. R. Bos, wishes to thank A. Gimenez, B.Sc. of the University of Washington, Seattle, U.S.A., for her improvements of the manuscript.

\begin{tabular}{|c|c|}
\hline$f$ & fugacity coefficient \\
\hline$F$ & molar flow rate, mols ${ }^{-1}$ \\
\hline$F(t)$ & $\begin{array}{l}\text { cumulative residence time distribution } \\
\text { function }\end{array}$ \\
\hline$\Delta H$ & enthalpy of reaction, $J \mathrm{~mol}^{-1}$ \\
\hline$k$ & rate constant \\
\hline$K_{\text {io }}$ & modified frequency factor \\
\hline$K_{\text {ia }}$ & activation energy, $\mathbf{J} \mathrm{mol}^{-1}$ \\
\hline$K_{\text {eq }}$ & equilibrium constant of reaction (1) \\
\hline$K_{\text {eq, }} \mathrm{CO}_{2}$ & equilibrium constant of reaction (2) \\
\hline$k_{\mathrm{g}}$ & $\begin{array}{l}\text { mass transfer coefficient in the gas phase, } \\
\mathrm{m} \mathrm{s}^{-1}\end{array}$ \\
\hline$N u$ & Nusselt number \\
\hline $\boldsymbol{P}$ & pressure, Pa \\
\hline$P^{\mathbf{o}}$ & standard state pressure $=0.1 \mathrm{MPa}$ \\
\hline$R_{\mathrm{CO}}$ & $\begin{array}{l}\text { reaction rate, mole } \mathrm{CO} \text { converted, } \\
\text { (kg cat) }{ }^{-1} \mathrm{~s}^{-1}\end{array}$ \\
\hline$R_{\mathbf{M}}$ & $\begin{array}{l}\text { reaction rate, mole methanol formed, } \\
\text { (kgcat) })^{-1} \mathrm{~s}^{-1}\end{array}$ \\
\hline $\boldsymbol{R}$ & gas constant $=8.3144 \mathrm{~J} \mathrm{~mol}^{-1} \mathrm{~K}^{-1}$ \\
\hline $\boldsymbol{R}$ & recycle ratio \\
\hline $\operatorname{Re}$ & Reynolds number \\
\hline$t$ & time, $s$ \\
\hline$T$ & temperature, $\mathbf{K}$ \\
\hline$v_{\mathbf{g}}$ & gas velocity, $\mathrm{m} \mathrm{s}^{-1}$ \\
\hline $\boldsymbol{W}$ & mass of catalyst, $\mathrm{kg}$ \\
\hline $\mathbf{x}$ & vector of independent variables \\
\hline$y$ & mole fraction \\
\hline$y^{*}$ & $\begin{array}{l}\text { mole fraction } \mathrm{CO} \text { after methanol conden- } \\
\text { sation }\end{array}$ \\
\hline$y$ & riables \\
\hline
\end{tabular}

$\begin{array}{ll}\text { Greek letters } \\ \alpha_{\mathrm{p}} & \text { particle heat transfer coefficient, } \\ \Sigma & \text { W m } \mathrm{m}^{-2} \mathrm{~K}^{-1} \\ \theta & \text { model parameter } \\ \tau & \text { residence time, } \mathrm{s}^{-1} \\ \zeta & \text { relative conversion } \\ \phi & \text { fugacity divided by standard-state press- } \\ & \text { ure }\end{array}$

Subscripts

$\begin{array}{ll}\text { i } & \text { component i } \\ \text { in } & \text { inlet } \\ \text { M } & \text { methanol } \\ \text { min } & \text { minimal } \\ \text { n } & \text { normal } \\ \text { out } & \text { outlet } \\ \text { ox } & \text { oxidized } \\ \text { p } & \text { particle }\end{array}$


red reduced

T total

\section{REFERENCES}

Agny, R. M. and Takoudis, C. G., 1985, Synthesis of methanol from carbon monoxide and hydrogen over a copper-zinc oxide-alumina catalyst. Ind. Engng Chem. Prod. Res. Dev. 24, $50-55$.

Amenomiya, Y. and Tagawa, T., 1984, Infrared study of methanol synthesis from $\mathrm{CO}_{2}$ and $\mathrm{H}_{2}$ on supported copper zinc oxide catalyst. Proc. 8 th Int. Cong. on Catalysis, Vol. II, pp. 557-567.

Atroschenko, V.I., Leonov, V. E. and Karavaev, M. M., 1971, The rate of formation of methanol on a zinc-chromium catalyst. Kinet. Katal. 12, 60.

Bardet, R., Thivolle-Cazat, J. and Trambouze, Y., 1984, C. $r$. Hebd. Séances Acad. Sci. Sér. C 299, 423.

BASF, 1979, S 3-85 Betriebsanleitung.

Berty, J. M., 1974, Reactor for vapor-phase catalytic studies. Chem. Engng Prog. 70, 78-84.

Bowker, M., Hyland, J. N. K., Vandervell, H. D. and Waugh, K. C., 1984, Proc. 8 th Int. Cong. on Catalysis, Vol. II, pp. $35-46$.

Broucek, R., 1983, Falsification of kinctic parameters by incorrect treatment of recirculation reactor data. Chem. Engng Sci. 38, 1349-1350.

Buzzi-Ferraris, G. and Donati, G., 1971, Analysis of the kinetic models for the reaction of synthesis of methanol. Ind. Chim. Ital. 7, 53.

Campbell, C. T., 1987, Comments on: "The activity and state of the copper surface in methanol synthesis". Appl. Catal. 32, 367-369.

Chinchen, G. C., Denny, P. J., Parker, D. G., Spencer, M. S. and Whan, D. A., 1987a, Mechanism of methanol synthesis from $\mathrm{CO}_{2} / \mathrm{CO} / \mathrm{H}_{2}$ mixtures over copper/zinc oxide catalysts: the use of ${ }^{14} \mathrm{C}$ labelled reactants. Appl. Catal. 30, 333-338.

Chinchen, G. C., Spencer, M. S., Waugh, K. C. and Whan, D. A., $1987 \mathrm{~b}$, Reply to comments on "The activity and state of the copper surface in methanol synthesis". Appl. Catal. 32, $371-373$.

Chinchen, G. C., Denny, P. J., Spencer, M. S. and Waugh, K. C., 1988, Synthesis of methanol. Part 1. Appl. Catal. 36, 167.

Cropley, J. B., 1987, Systematic errors in recycle reactor kinetic studies. Chem. Engng Prog. 2, 46-51.

Denny, P. J. and Whan, D. A., 1978, The heterogeneously catalysed hydrogenation of carbon monoxide. Catalysis, Spec. Rep., Chem. Soc., London 2, 46.

Georgakopoulos, K. and Broucek, R., 1987, An investigation of the non-ideality of an internal recycle reactor using a concentration controlled test reaction. Chem. Engng Sci. 42, 2782-2784.

Ghiotti, G. and Boccuzzi, F., 1987, Chemical and physical properties of copper-based catalysts for $\mathrm{CO}$ shift reaction and methanol synthesis. Catal. Rev.-Sci. Engng 29, $151-182$.

Klaus, R. A., 1981, A computer based methodology for regression and experimental design with non-linear algebraic and ordinary differential equation multi-response models. Thesis, ETH, Zürich.

Klaus, R. A. and Rippin, D. W. T., 1979, A new flexible and easy to use general purpose regression program for handling a variety of single- and multi-response situations. Comp. Chem. Engng 3, 105-115.

Klier, K., Chatikavnij, V., Herman, R. G. and Simmons, G. W., 1982, The catalytic synthesis of methanol from $\mathrm{CO} / \mathrm{H}_{2}$ IV: the effects of carbon dioxide. J. Catal. 74, 343-360.

Kuczynski, M., Browne, W. I., Fontein, H. J. and Westerterp, K. R., 1987a, Reaction kinetics of the synthesis of methand from $\mathrm{CO}$ and $\mathrm{H}_{2}$ on a copper cataiyst. Chem. Engng Process. 21, 179-191.

Kuczynski, M., Oyevaar, M. H., Pieters, R. T. and Westerterp, K. R., 1987b, The methanol synthesis in a countercurrent gas-solid-solid trickle flow reactor. An experimental study. Chem. Engng Sci. 42, 1887-1898.

Kung, H. H., 1980, Methanol synthesis. Catal. Rev. 22. 235-259.

Leonov, V. E., Karabaev, M. M., Tsybina, E. and Petrishcheva, G. S., 1973, Study of the kinetics of the methanol synthesis on a low temperature catalyst. Kinet. Katal. 14, 970.

Liu, G., Wilcox, D., Garland, D. and Kung, H. H., 1984, The rate of methanol production on a copper-zinc oxide catalyst: the dependence on the feed gas composition. $J$ Catal. 90, 139-146.

Mehta, S., Simmons, G. W., Klier, K. and Herman, R. G., 1979 , The catalytic synthesis of methanol from $\mathrm{CO} / \mathrm{H}_{2} . J$. Catal. 57, 339-360.

Natta, G., Pino, P., Mazzanti, M. and Pasquon, I., 1953, Kinetic interpretations of heterogeneous catalysis and their application to reaction between gases at high pressure. 1. Synthesis of methanol. Ing. Chim. Milan 35, $705-724$.

Peng, D. and Robinson, D. B., 1976, A new two-constant equation of state. Ind. Engng Chem. Fundam. 15, 59-65.

Reid, R. C., Prausnitz, J. N. and Sherwood, T. K., 1977, The Properties of Gases and Liquids (3rd edn). McGraw-Hill, New York.

Schermuly, O. and Luft, G., 1977, The low pressure synthesis of methanol in a jet-loop reactor. Chem. Ing. Techn. 49, 907.

Seyfert, W. and Luft, G., 1985, Untersuchungen zur Methanolsynthese im Mitteldruckbereich, Chem. Ing Techn. 57, 482-483.

Shub, D. A., 1983, Methanol synthesis on a $\mathrm{Zn} / \mathrm{Cr}$ catalyst: establishment of stationary rate. Kinet. Catal. 24, 323-326.

Skrzypek, J., Grzesik, M. and Sropa, R., 1985, Chem. Engng Sci. 40, 671-673.

Smith, K. J., 1987, Comments on "The synthesis of alcohols from carbon dioxide and hydrogen. 1. The kinetics of the methanol synthesis". Ind. Engng Chem. Res. 26, 400-401.

Stephen, H. and Stephen, T., 1963, Solubilities of Anorganic and Organic Compounds, Vol. 1, Binary Systems. Pergamon Press, London.

Takagawa, M. and Oshugi, M., 1987, A study on reaction rates for methanol synthesis from carbon monoxide, carbon dioxide and hydrogen. J. Catal. 107, 161-172.

Tiltscher, H. and Hofmann, H., 1987, Trends in high pressure chemical reaction engineering. Chem. Engng Sci. 42, 959-977.

Vedage, G. A., Pitchai, R., Herman, R. G. and Klier, K., 1984, Water promotion and identification of intermediates in methanol synthesis. Proc. 8th Int. Cong. on Catalysis, Vol. II, p. 47.

Villa, P., Forzatti, P., Buzzi-Ferraris, G., Garone, G. and Pasquon, I., 1985, The synthesis of alcohols from carbon dioxide and hydrogen. 1. The kinetics of the methanol synthesis. Ind. Engng Chem. Proc. Des. Dev. 24, 12-19.

Villa, P., Forzatti, P., Buzzi-Ferraris, G., Garone, G. and Pasquon, I., 1987, Reply to comments on "The synthesis of alcohols from carbon dioxide and hydrogen. 1. The kinetics of the methanol synthesis". Ind. Engng Chem. Res. 26, 402-403.

Wedel, S. and Villadsen, J., 1983, Falsification of kinetic parameters by incorrect treatment of recirculation reactor data. Chem. Engng Sci. 38, 1346-1349.

Westerterp, K. R., van Swaaij, W. P. M. and Beenackers, A A. C. M., 1984, Chemical Reactor Design and Operation. Wiley, Chichester.

Westerterp, K. R. and Kuczynski, M., 1987, A model for a countercurrent gas-solid-solid trickle flow reactor for equilibrium reactions. The methanol synthesis. Chem. Engng Sri. 42, 1871-1885. 